DOI: 10.21767/2172-0479.100027

\section{Orbital Complications of The Paranasal Sinuses Disease}

\section{Abstract}

Introduction: The close relationship between diseases of the paranasal sinuses system and the orbit is based on their anatomical relationship. About $60 \%$ to $80 \%$ of the osseous eye socket is made up by sinus walls.

Objective: To describe evaluation of orbital complications in patient with paranasal sinuses diseases at Dr. M. Djamil Hospital Padang for 2005-2014.

Method: Descriptive study we obtained from medical record of patients during January 2005- December 2014. Data collected including age, sex, diagnosis of paranasal sinuses diseases, involved sinuses, orbital involvement and ocular presentations.

Results: There were fifty five patients came to Ophthalmology Department Dr. M. Djamil Hospital Padang during period 2005-2014, either directly came or consulted from ENT Department, with suspicion of orbital involvement resulted from prior paranasal sinuses diseases, 34 (61.8\%) male and 21 (38.2\%) female. The age of patients range between 4 y.o. to 83 y.o., with the most common range of age was between 51 to 60 y.o. Orbital involvelment occurred in 45 patients (81.8\%) while 10 patients $(18.2 \%)$ had no orbital involvement. Orbital infiltration was caused by sinonasal tumor in 35 patients $(77.7 \%)$, by sinus infection in 8 patients $(17.7 \%)$, and by mucocele in 2 patients (4.6\%). Sinonasal tumor was the most common paranasal sinuses disease which diagnosed in 43 patients (78.2\%) and maxillary sinus $(58.1 \%)$ was the most common involved sinus. Majority of the patients (67.7\%) had presented with proptosis followed by ophthalmoplegia (54.8\%) and visual acuity reduction (43.5\%).

Conclusion: The most common affected person were men and more frequently found in range of age between 51 to 60 y.o. Sinonasal tumor was the most etiology of orbital abnormalities in the the present of paranasal sinuses disease with maxillary sinus was the most common involved sinus. Proptosis was the major ocular presentation which found in orbital complications caused by paranasal sinuses diseases.

Keywords: Orbital involvelment; Paranasal sinus disease

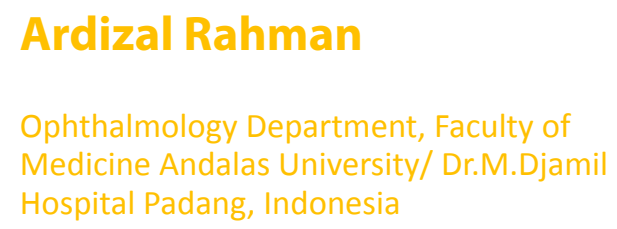

Corresponding author: Ardizal Rahman

ardizalrahman@yahoo.com

Faculty of Medicine Andalas University/ Dr.M.Djamil Hospital Padang, Indonesia.

Tel: +62811660650

Citation: Rahman A. Orbital Complications of The Paranasal Sinuses Disease. Transl Biomed. 2015, 6:3.

\section{Introduction}

A close relationship between diseases of the paranasal sinuses and the orbit is based on anatomical relationships. Orbital position adjacent to the nose and paranasal sinuses, makes it susceptible to the disease from the area. Orbital wall was related to the superior with frontal sinus floor, to the medial with lateral wall of the ethmoid sinus, to the inferior with the roof of the maxillary sinus and to the posteromedial with anterolateral wall of the sphenoid sinus. Approximately $60 \%$ to $80 \%$ of the wall of the orbit formed by the walls of the paranasal sinuses. In addition, the frontal sinus floor and the lateral wall of the ethmoid sinus walls were thin so that it has a weak resistance against a mass or an inflammatory process [1,2].

Paranasal sinuses and orbital involvement can simultaneously occur caused by lesions that originate from sinonasal region or disorder involving sinus and orbital simultaneously, such 
as traumatic lesions. Paranasal sinus disease complications in addition to the structure of the orbit is quite rare that includes an extension to the intracranial. Generally these circumstances is concurrent with complications in orbit but in rare cases can occur as an isolated complication [2-4].

Patients with diseases of the paranasal sinuses may show only ocular symptoms without rhinologic symptoms. Knowledge of the pathological condition in this case need to know to provide proper management. Management of the disease in the orbit that occur secondary to lesions in the paranasal sinuses thus also requires the role of otorhinolaryngologist other than ophthalmologist [2-4].

\section{Method and Result}

\section{Objective}

To know the description of paranasal sinus disease with involvement of the orbit in RS Dr. M. Djamil Padang

\section{Method}

The method used in this study was a retrospective descriptive study. Data taken from the patient's medical record during the period of January 2005-December 2014 and grouped according to age, gender, paranasal sinus disease, sinus involved, orbital involvement and clinical symptoms.

\section{Result}

During the period of January 2005-December 2014 there were 55 patients with primary disease in the paranasal sinuses with suspicion of secondary complication of the orbit were consulted to the Ophthalmology Department of Dr. M. Djamil Hospital Padang.

The largest group of age are in the range of $51-60$ years $(29.1 \%$, $\mathrm{n}=16$ ). The youngest patient age in this study is 4 years old and the oldest is 83 years old. Frequency of age groups according to each disease, sinusitis are most common in the age group of 1120 years with 4 patients (44.4\%), sinonasal tumor in the age group of $51-60$ years as many as 13 patients (30.2\%), and mucocele in age group of 0-10 years as many as 2 patients (66.7\%) (Table 1).

Table 1 Distribution by group of age with paranasal sinus disease diagnose.

\begin{tabular}{|c|c|c|c|c|}
\hline $\begin{array}{c}\text { Group of Age } \\
\text { (years) }\end{array}$ & Sinusitis & $\begin{array}{c}\mid c \\
\text { Sinonasal } \\
\text { Tumor }\end{array}$ & Mucocele & Total \\
\hline $0-10$ & $1(11.1 \%)$ & - & $2(66.7 \%)$ & $3(5.5 \%)$ \\
\hline $11-20$ & $4(44.4 \%)$ & $1(2.3 \%)$ & - & $5(9.1 \%)$ \\
\hline $21-30$ & $1(11.1 \%)$ & $2(4.7 \%)$ & - & $3(5.5 \%)$ \\
\hline $31-40$ & $1(11.1 \%)$ & $12(27.9 \%)$ & - & $13(23.6 \%)$ \\
\hline $41-50$ & - & $8(18.6 \%)$ & - & $8(14.5 \%)$ \\
\hline $51-60$ & $2(22.2 \%)$ & $13(30.2 \%)$ & $1(33.3 \%)$ & $16(29.1 \%)$ \\
\hline $61-70$ & - & $5(11.6 \%)$ & - & $5(9.1 \%)$ \\
\hline $71-80$ & - & $1(2.3 \%)$ & - & $1(1.8 \%)$ \\
\hline $81-90$ & - & $1(2.3 \%)$ & - & $1(1.8 \%)$ \\
\hline Total & $9(100.0 \%)$ & $43100.0 \%)$ & $3(100.0 \%)$ & $55(100.0 \%)$ \\
\hline & & & & \\
\hline
\end{tabular}

Male patients $(61.8 \%)$ more common than women $(38.2 \%)$ with a ratio of 1.6: 1 (Table 2).

Sinonasal tumor $(78.2 \%, n=43)$ is the largest paranasal sinus disease were found in this study. It appears that the disease in the paranasal sinuses have a tendency to expand into orbit wheter sinusitis $(88.9 \%, n=8)$, sinonasal tumor $(81.4 \%, n=35)$ or mucocele (66.7\%, $n=2$ ) (Table 3).

In this study histopathological examination only showed in 18 patients with sinonasal tumors. Sinonasal tumor types that most common are squamous cell carcinoma which found in 8 patients (Table 4).

Involvement can occur more than 1 paranasal sinuses on each of the patients with paranasal sinus disease and maxillary sinus $(58.1 \%, \mathrm{n}=36)$ are the most common involved sinus. Maxillary sinus $(46.2 \%, n=6)$ and ethmoid $(38.5 \%, n=5)$ is the highest sinus involved in the sinus infection. Most sinonasal tumors found in the maxillary sinus $(66.7 \%, n=30)$ while mucocele more common involved the frontal sinus $(50 \%, n=2)$ (Table 5).

In each of the patients with paranasal sinus disease, generally more than 1 ocular symptom were found. Proptosis is the highest

Table 2 Distribution by sex

\begin{tabular}{|c|c|c|}
\hline Sex & Frequency & Percentage (\%) \\
\hline Male & 34 & 61.8 \\
\hline Female & 21 & 38.2 \\
\hline Total & 55 & 100.0 \\
\hline
\end{tabular}

Table 3 Distribution of diagnosis according to the paranasal sinus disease with involvement of the orbit.

\begin{tabular}{|c|c|c|c|}
\hline \multirow{2}{*}{ Diagnose } & \multicolumn{2}{|c|}{ Orbital Involvement } & \multirow{2}{*}{ Total } \\
\hline & Yes & No & \\
\hline \multirow{3}{*}{$\begin{array}{c}\text { Sinusitis } \\
\text { Sinonasal Tumor } \\
\text { Mucocele }\end{array}$} & $8(88.9 \%)$ & $1(11.1 \%)$ & 9 (16.4\%) \\
\hline & 35 (81.4\%) & $8(18.6 \%)$ & $43(78.2 \%)$ \\
\hline & $2(66.7 \%)$ & $1(33.3 \%)$ & $3(5.5 \%)$ \\
\hline Total & $45(81.8 \%)$ & $10(18.2 \%)$ & $55(100 \%)$ \\
\hline
\end{tabular}

Table 4 Distribution by type of histopathology in sinonasal tumors.

\begin{tabular}{|l|c|}
\hline \multicolumn{1}{c}{ Histopathology type } & Frequency \\
\hline Squamous cell carcinoma & 8 \\
\hline Adenoid cystic carcinoma & 3 \\
\hline Sinonasal undifferentiated carcinoma & 2 \\
\hline Mucoepidermoid carcinoma & 1 \\
\hline Olfactory neuroblastoma & 1 \\
\hline Lymphoma maligna & 2 \\
\hline Papilloma sinonasal & 1 \\
\hline Total & 18 \\
\hline
\end{tabular}

Table 5 Distribution according to diagnosis of paranasal sinus disease with sinus involved.

\begin{tabular}{|c|c|c|c|c|}
\hline \multirow[b]{2}{*}{ Diagnose } & \multicolumn{4}{|c|}{ Percentage of involved sinus } \\
\hline & $\begin{array}{l}\text { Maxillary } \\
\text { sinus }\end{array}$ & $\begin{array}{l}\text { Ethmoid } \\
\text { Sinus }\end{array}$ & Frontal sinust & $\begin{array}{l}\text { Sphenoid } \\
\text { sinus }\end{array}$ \\
\hline Sinusitis & $6(46.2 \%)$ & $5(38.5 \%)$ & $2(15.4 \%)$ & - \\
\hline $\begin{array}{l}\text { Sinonasal } \\
\text { Tumor }\end{array}$ & $30(66.7 \%)$ & $6(13.3 \%)$ & $3(6.7 \%)$ & $6(13.3 \%)$ \\
\hline Mucocele & - & $1(25.0 \%)$ & $2(50.0 \%)$ & 1 (25.0\%) \\
\hline Total & 36 (58.1\%) & 12 (19.3\%) & 7 (11.3\%) & 7 (11.3\%) \\
\hline
\end{tabular}


manifestation of ocular symptoms $(67.3 \%, n=37)$ due to diseases of the paranasal sinuses. Other ocular symptoms that common were ophthalmoplegic $(56.4 \%, n=31)$ and visual loss $(43.6 \%$, $n=24$ ) (Table 6).

In patients with sinusitis complications such as orbital cellulitis in 6 patients, 5 patients treated with intravenous antibiotics and one person refused to therapy. Complications include eyelid and periorbital abscess in 2 other sinusitis patients where the two patients underwent drainage of abscesses and administration of intravenous antibiotics. In patients with sinonasal tumors that have invaded the orbit, exenteration carried in 23 patients, 6 patients only performed excisional biopsy for histopathological examination. Radiotherapy conducted in 2 patients with intracranial complication, and 4 patients refused exenteration because patients feel no complaint in vision. In the 2 patients with mucocele and orbital complication, in 1 patient with sfenoethmoid sinus mucocele, celeplasty was done and in 1 patient with frontal sinus mucocele, only aspiration biopsy was done for culture and cytology (Table 7).

\section{Discussion}

During the periodof January 2005-December 2014 there were 55 patients with diseases of the paranasal sinuses which suspected of involvement in the orbit. Patients age range are wide enough that from the age of 4 years up to the age of 83 years. In general, the largest age group are in the age range $51-60$ years $(29.1 \%$, $\mathrm{n}=16)$. In the study by Sajid et al. age range of the patients obtained also broad enough that from the age of 1-75 years with the largest age group is $31-40$ years $(26.67 \%)$. If we observed tendency of age according to each disease, sinusitis are most common in the age group 11-20 years as many as 4 patients (44.4\%), sinonasal tumors in the age group $51-60$ years as many as 13 patients $(30.2 \%)$, and mucocele group age $0-10$ years as many as 2 patients $(66.7 \%)$. In the literature mentioned that sinusitis is more prevalent in younger patients while malignancy of the paranasal sinuses tend to occur in patients with old age [3].

In this study, male patients found more common than women by a ratio of 1.6: 1 . Although in another study by Yousry and Malik et al. also found the number of male patients were more common than women by a ratio of respectively 3.5: 1 and 2: 1 but Sajid et al. get the opposite result with the ratio of men compared to women is 1: 4 [2-4].

From the 55 patients with paranasal sinus disease, 45 (81.8\%) of them have been found the extent of disease to orbit and sinonasal tumors $(78.2 \%)$ is the paranasal sinus disease with is most frequent compared with sinusitis and mucocele. This is different from previous studies where sinusitis is the most paranasal sinus disease with complications to the orbit with a frequency of $60 \%$ to $75 \%$ of the total patients [2-4].
The use of antibiotics and the wide availability and advancement of diagnostic techniques such as CT scans and MRI is now believed to have significantly decreased the morbidity and complications due to sinusitis $[4,5]$.

Histopathological examination was found in 18 patients with sinonasal tumors with tumor type that most common are squamous cell carcinoma in 8 patients (44.4\%). Other tumor types obtained is adenoid cystic carcinoma in 3 patients, sinonasal undifferentiated carcinoma in 2 patients, mucoepidermoid carcinoma and olfactory neuroblastoma each in 1 patient. Nonepitelial types of malignant tumors such as lymphoma also found in 2 patients. Sinonasal papilloma which is a benign tumor was found in 1 patient.

Sinonasal tumors constitute $1 \%$ of all malignant tumors and $3 \%$ of the otolaryngology tumor. In the literature mentioned that squamous cell carcinoma is the most common malignant sinonasal tumors (80\%) and generally comes from the maxillary sinus. These tumors are generally found in middle or advanced age. Sajid et al. in his research also found squamous cell carcinoma as the most sinonasal tumors with a frequency of $75 \%$ of the entire tumor [2-4].

On this study, orbital cellulitis is a common complication of sinusitis were found in 6 patients (75\%). In the other 2 patients got complications of periorbital abscess and eyelid abscess. Acute bacterial sinusitis, especially when the ethmoid sinuses are involved, is a major cause of infection in orbit. Approximately $60 \%$ $-80 \%$ of cases of orbital cellulitis is an extension of the secondary bacterial sinusitis. By contrast, only $0.5 \%-3.9 \%$ of cases of bacterial sinusitis complications that cause orbital cellulitis [6-9].

Mucocele of paranasal sinuses pretty much mentioned in the literature that is equal $4-8.5 \%$ of the disease with the expansion into the orbit. In this study there were 3 patients (5.5\%) with mucocele, 2 patients with frontal sinus and 1 patient with ethmoid and sphenoid sinuses mucocele. Malik et al. just get the case of mucocele in 1 patient $(1.85 \%)$ involving the ethmoid sinuses while Yousry get 2 patients (7\%) with mucocele of the frontal and ethmoid sinuses $[2,4]$.

From the 55 cases of paranasal sinus disease in this study, the maxillary sinus (58.1\%) are the most involved sinus. Sajid et al. found that the ethmoid sinus (50\%) are most involved sinus. Maxillary sinus (46.2\%) and ethmoid (38.5\%) is the highest sinus involved in the sinus infection. Mekhiterian et al. also found that the maxillary sinus (60\%) are the most widely sinus involved in acute sinusitis in children. Most sinonasal tumors found in the maxillary sinus (66.7\%) while mucocele more commonly involved the frontal sinus (50\%). Frontonasal long duct obstruction causing vulnerability in the duct so that the frontal sinus is a common occurrence mucocele location $[3,6,10]$.

Table 6 Distribution by paranasal sinus disease diagnosis which have orbital complication with ocular symptoms.

\begin{tabular}{|c|c|c|c|c|c|c|}
\hline Diagnose & Proptosis & Ophthalmoplegic & Vcular Symptoms & Diplopia & Ptosis \\
\hline Sinusitis & $6(66.7 \%)$ & $5(55.6 \%)$ & $3(33.3 \%)$ & $2(22.2 \%)$ & $1(11.1 \%)$ \\
\hline Sinonasal Tumor & $29(67.4 \%)$ & $24(55.8 \%)$ & $20(46.5 \%)$ & $12(27.9 \%)$ & $4(9.3 \%)$ \\
\hline Mucocele & $2(66.7 \%)$ & $2(66.7 \%)$ & $1(33.3 \%)$ & $1(33.3 \%)$ & - \\
\hline Total & $37(67.3 \%)$ & $31(56.4 \%)$ & $24(43.6 \%)$ & $15(27.3 \%)$ & $5(9.1 \%)$ \\
\hline
\end{tabular}


Table 7 Distribution according to paranasal sinus disease diagnosis which have orbital complication with the management of therapy.

\begin{tabular}{|c|c|c|}
\hline Diagnose & Therapy & Frequencyi \\
\hline \multirow{3}{*}{ Sinusitis } & Intravenous antibiotic & 5 \\
\cline { 2 - 3 } & Abcess drainage and Intravenous antibiotic & 2 \\
\hline \multirow{3}{*}{$\begin{array}{c}\text { Sinonasal } \\
\text { Tumor }\end{array}$} & Refuse treatment & 1 \\
\hline \multirow{2}{*}{ Mucocele } & Exenteration & 23 \\
\hline & Excision Biopsy & 6 \\
\hline & Radiotherapy & 2 \\
\hline & Refuse treatment & 4 \\
\hline & Cele plasty & 1 \\
\hline & Aspiration Biopsy & 1 \\
\hline
\end{tabular}

In this study, found that the highest manifestation of ocular symptoms of the disease in the paranasal sinuses is proptosis $(67.3 \%, n=37)$. Other ocular symptoms that common are ophthalmoplegic $(56.4 \%, n=31)$ and visual loss $(43.6 \%, n=24)$. Generally there are more than 1 ocular symptoms were found in each patient. Sajid et al. also found proptosis $(66.66 \%)$ as the largest clinical manifestations followed by a decrease in visual acuity (25.9\%) and ophthalmoplegia (11:11\%). Direction which occur proptosis can be an important clue of the location of the paranasal sinuses that involved. Most patients with sinonasal tumors in this study had involvement in the maxillary sinus, causing proptosis toward the superior, accompanied swelling of the cheeks. In patients with frontal mucocele proptosis occur towards inferolateral accompanied by swelling of the brow area. Proptosis in sinusitis with orbital complications occur due to inflammation and diffuse edema in the soft tissues of the orbit. The presence of subperiosteal abscess will drive eyeballs to a certain direction. In this study, proptosis occur laterally in 1 patient with periorbital abscess $[3,11]$.

Ocular manifestations in the form of a decrease in visual acuity showed the presence of optic nerve involvement. The underlying pathophysiology may be caused by direct compression on the nerve lesions, nonperfusion of the blood vessels that lead to ischemic orbital nerve or inflammation in response to infection around the nerve. In this study, there is a decrease in visual acuity to no light perception in 5 patients with sinonasal tumors and 1 patient with sinusitis.

Ophthalmoplegia can be caused by a mechanical restriction on extraocular muscles or nerves paresis innervating the extraocular muscles. Force duction test can distinguish between the causes of which the results of the test will be positive if the etiology is due to mechanical restrictions. Abnormal ocular motility can cause diplopia both at the primary gaze position and the position of the extremes gaze $[12,13]$.

Management of patients with paranasal sinus disease with complication of the orbit conducted jointly by Ophthalmology and ENT Department of Dr. M. Djamil Hospital Padang. In patients with sinusitis complications such as orbital cellulitis in 6 patients, 5 patients treated with intravenous antibiotics and one person refused to be admitted and given treatment for economic reasons. Intravenous antibiotics given was third-generation cephalosporin such as ceftriaxone and ceftazidime. Complications such as eyelid and periorbital abscess in 2 other sinusitis patients was drainage of abscesses and administration of intravenous antibiotics. In patients with sinonasal tumors that have invaded the orbit, exenteration carried to 23 patients. On 6 patients only performed excisional biopsy for histopathological examination and the patient did not come back for control. Radiotherapy conducted in 2 patients with intracranial complication, and 4 patients refused exenteration because patients feel no complaint in vision. In the 2 patients with mucocele and orbital involvement, in 1 patient with sfenoethmoid sinus mucocele, celeplasty was done to correct the excretion sinus tract and the other patients with frontal sinus mucocele only aspiration biopsy was done for culture and cytology.

\section{Conclusion}

Diseases of the paranasal sinuses with the complication of the orbit is most prevalent in the age group of 51-60 years. Sinusitis and mucocele are most common in the younger age group whereas sinonasal tumors most common in older age groups. Diseases of the paranasal sinuses with more involvement of the orbit was found in the male patient more commonly than women by a ratio of 1.6: 1 . Of the total patients with paranasal sinus disease, there is a high tendency for expansion of the disease to the orbit. Sinonasal tumors is a paranasal sinus disease with the highest frequency compared with sinusitis and mucocele while most tumor types are squamous cell carcinoma. Maxillary sinus is a sinus most involved in the paranasal sinus disease with complication of the orbit. Most ocular manifestations of the disease in the paranasal sinuses is proptosis. Proptosis found is nonaxial proptosis which had opposite direction to the lesion. 


\section{References}

Bier H, Ganzer U (1990) Involvement of the Orbit in Diseases of the Paranasal Sinuses. Neurosurg Rev 13: 109-110.

El-Sayed Y (1995) Orbital Involvement in Sinonasal Disease. Saudi J of Ophthalmol 9: 29-37.

3 Sajid T, Kazmi HS, Shah SA, Ali Z, Khan F, et al. (2011) Complications of Nose and Paranasal Sinus Disease. J Ayub Med Coll Abbottabad 23: 56-59.

4 Malik TG, Farooq K, Rashid A (2011) Paranasal Sinuses and Nasal Cavity; The Notorious Neighbours of Orbit. Professional Med J 18 : 154-159.

5 Lund VJ (1997) The Orbit. In: Scott-Brown's Otorhinolaryngology. Volume 4. London: Butterworth-Heinemann 590-603.

- Mekhitarian NL, Pignatari S, Mitsuda S, Fava AS, Stamm A (2007) Acute sinusitis in children: a retrospective study of orbital complications. Braz J Otorhinolaryngol 73: 75-79.
Feldon SE, Orbital Cellulitis and Paranasal Sinus Disease. 147-50.

8 De Campos Sobrinho ALP, Azoubel E, da Silva CK, Andrade MGS (2006) Serious Orbital Infection Secondary to Paranasal Sinusitis. Clin Pesq Odontol Curitiba 2: 429-435.

9 Skuta GL, Cantor LB, Weiss JS (2011) Orbital Anatomy. In: Orbits, Eyelids, and the Lacrimal System. San Francisco: American Academy of Ophthalmology 5-8, 17-9.

10 Jones HM (1981) Some Orbital Complications of Nose and Throat Conditions. J of the Royal Soc of Med 74: 409-414.

11 Choi SS, Grundfast KM (2001) Complications in Sinus Disease. In: Disease of the Sinuses: Diagnosis and Management. London: B.C. Decker Inc 169-172.

2 Lee AG (2005) Neuro-Ophthalmologic Evaluation of the Orbit. In: Orbital Tumors Diagnosis and Treatment. New York: Springer Science 61-72.

13 Hintschich C, Rose G (2010) Orbital Tumors. In: Oncology of CNS Tumors. Berlin: Springer-Verlag 309-313. 